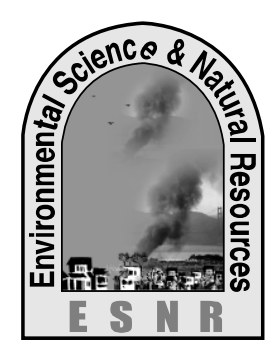

\title{
Development and Characterization of a Biodegradable Colored Film Based on Starch and Chitosan by Using Acacia Catechu
}

\author{
F. B. Quader ${ }^{1}$ R. A. Khan ${ }^{2}$, M. A. Islam ${ }^{1}$, S. Saha ${ }^{1}$, and K. N. Sharmin ${ }^{3}$ \\ ${ }^{1}$ Dept. of Applied Chemistry and Chemical Technology, ${ }^{3}$ Dept. of Applied Food Science \\ and Nutrition, Chittagong Veterinary and Animal Sciences University, Chittagong-4225, \\ Bangladesh \\ ${ }^{2}$ Institute of Radiation and Polymer Technology, Bangladesh Atomic Energy \\ Commission, Savar, Dhaka, Bangladesh \\ *Corresponding author: fahadbinquader@gmail.com
}

\begin{abstract}
Green technology like biodegradable films using natural polymer is an obvious need of today. Attempt of this experiment was aimed at development and characterization of a biodegradable colored film based on starch and chitosan by using Acacia catechu. Chitosan reinforced starch based biodegradable composite film was prepared by casting. The chitosan content in the films was varied from 20 $80 \%(\mathrm{w} / \mathrm{w})$. Tensile strength (TS) was improved significantly with the addition of chitosan but the elongation at break (EB \%) of the composite decreased. With the addition of the Acacia catechu, tensile strength of the composites improved more. The acacia content of the film was varied from $0.05-0.2(\mathrm{w} / \mathrm{w})$. The good thermal stability of this prepared film was confirmed by thermo-gravimetric analysis. Structural characterization was done by Fourier transform infrared radiation spectroscopy. Surface morphology of the composite film was examined by scanning electron microscope (SEM) which suggested sufficient homogenization of starch, chitosan and Acacia catechu. Water uptake was found lower for final composites in the comparison to starch/chitosan and chitosan film. The satisfactory rate of degradation in the soil is expected that the final composite film within less than 6 months. The developed films intended to use as the alternative of synthetic non biodegradable colored packaging films.
\end{abstract}

Key words: Composite, Green technology, Packaging

\section{Introduction}

The production of plastic materials has been increasing considerably due to the extensive growth of the world population. Global plastic production grows $4 \%$ annually, creating hundreds of tons of residues daily (Arandes et al., 2004). Generally, plastic products are derived from non-renewable fossil fuels and are nonbiodegradable (Pagella et al., 2002; Ban et al., 2006). The improper disposal of the enormous volume of petroleum-derived plastics leads to environmental pollution and raises the question how to replace them with natural polymers, being biodegradable and renewable resources (et al., 2008). Biological recycling of polymers must be considered as an alternative to more traditional recycling procedures and this has stimulated researchers to synthesize new polymers that can be returned to the biological cycle after use. Therefore the use of agricultural biopolymers that are easily biodegradable would solve these problems (Parra et al., 2004). Over the last few years, the interest in biodegradable films and films made from renewable and natural polymers has increased. Currently, many researches are devoted to starch and chitosan, because these are inexpensive and the most abundant natural polymers. Starch, a natural renewable polysaccharide from a great variety of crops, is one of the promising raw materials for the production of biodegradable plastics because of its low cost, availability as a renewable resource, biodegradable and the innocuous degradation products. It has already been widely researched as an important raw material for environmental biomedical applications. Starch is a carbohydrate consisting of a large number of glucose units joined together by glycosidic bonds. It consists of two types of molecules: the linear and helical amylose and branched amylopectin (Wikipedia, 2015). But pure starch based materials are hydrophilic and their mechanical properties decrease with water intake (Shorgen; Mathew et al., 2002). The application of pure starch films extremely limited due to the high hydrophiliicity and deficient mechanical properties of starch (Xu et al., 2004 and Thuwall et al., 2006). To overcome this behavior, starch can be blended with other polymeric material (Wang et al., 2003) like chitosan. Chitosan is produced via chitin which is obtained generally from prawn or crab shell wastes by deproteinizaton and demineralization processes. Chitin is second most abundant natural polymeric material. It is a linear polysaccharide composed of 2-acetamido-2deoxy-D-glucosidic bonds. Conversely, chitosan is an aminopolysaccharide comprising an unbranched chain of $\beta$ (1 $\square 4$ )2-2-amino-2-deoxy-Dglucopyranose residue. Chitosan has been extensively studied in pharmaceutical and medical fields for its biodegradability, biocompatibility, bioactivity and interesting physicochemical properties partially acetylated chitosan that has about $50 \%$ D-glucosamine unit is only able to dissolve in water (Wang et al., 2003). This biopolymer is bio-renewable, biodegradable, and bio-functional. The presence of active groups is chitosan molecules favored it to use in many fields. Chitosan films are now used in making biodegradable packaging material. Several studies have indicated the bacteriostatic (Chen et al., 1996, Helander et al., 2001, and Moller et al., 2004) and fungistatic (Roller et al., 1999) activities of chitosan. Because of reactive amino and hydroxyl functional groups, chitosan is frequently blended with other polymers (Garcia et al., 2009). Starch and chitosan are hydrocolloids with well-known good film forming capacities. Both have been reported as potential materials for packaging. For coloring film a natural resin acacia catechu or Khair is used. Khair (Acacia catechu) is a moderate size deciduous tree with rough dark gray brown bark. It belongs to family 
Leguminoseae-mimoseae (Frienvis.nic.in, 2015). The most important product obtained from Acacia catechu var. catechu proper is Khair or catechu. This is obtained by boiling chips of heartwood with water in specially designed earthen pitchers and allowing the concentrate to cool and crystallize (Frienvis.nic.in, 2015). As sold in the bazaar, catechu is found in irregular pieces or small square blocks of grayish black color, which on breaking show a crystalline fracture (Frienvis.nic.in, 2015). Color of catechu-water solution is dark brown. This solution is acidic in nature. The chief chemical constituent of catechu is catechin. Catechin is poly phenolic antioxidant plant secondary metabolite (Wikipedia, 2015). The IUPAC name is $(2 R$, 3S)-2-(3, 4dihydroxyphenyl)-3, 4-dihydro- $2 H$-chromene-3, 5, 7triol. Catechin possesses two benzene rings (called the A- and B-rings) and a dihydropyranheterocycle (the Cring) with a hydroxyl group on carbon 3 . The A ring is similar to a resorcinol moiety while the $\mathrm{B}$ ring is similar to a catechol moiety. There are two chiral centers on the molecule on carbons 2 and 3. It has therefore four diastereoisomers. Two of the isomers are in transconfiguration and are called catechin and the other two are in cis-configuration and are called epicatechin
(Wikipedia, 2015). Catechin oxygenase, a key enzyme in the degradation of catechin, is present in fungi and bacteria (Arunachalam et al., 2003). The objective of the present research was developing colored films based on starch and chitosan by using acacia catechu. The mechanical properties of the prepared films were measured. Molecular interactions of components present in films were examined by Fourier Transform Infrared (FT-IR) spectroscopy. Thermal properties of the films were investigated by Differential Scanning Calorimetric (DSC) studies. Scanning Electron Microscopy (SEM) investigated surface topography of the films. The water uptake and the degradation test in soil were also performed.

\section{Materials and Methods}

\section{Materials}

Chitosan from crab shell (powder form; viscosity of 200 $\mathrm{cP}$ ) and starch (potato, powder form) were purchased from sigma - Aldrich Chemie GmbH, Germany. Acacia catechu was bought from the local market of Bangladesh. The chemical formula of chitosan, Starch and acacia catechu were given in Fig. 1.

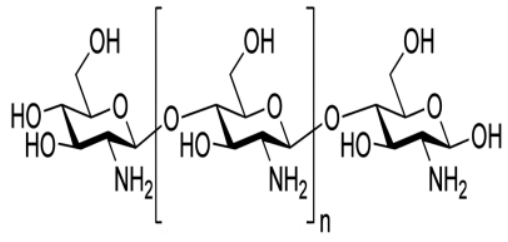

(a)

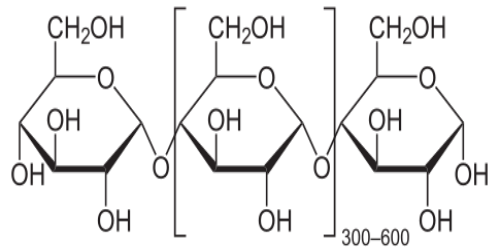

(b)

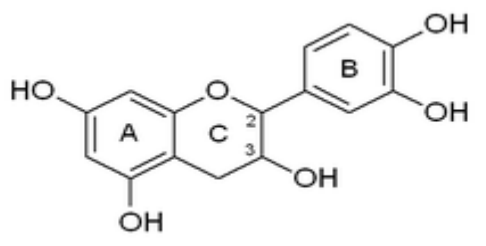

(c)

Fig. 1. Structure of chitosan (a), starch (b) and catechin (c)

\section{Preparation of bio-polymeric films by casting}

At first, 1\% chitosan solution (w/w) was prepared using $2 \%(w / w)$ acetic acid solution. Films of chitosan were prepared by casting the chitosan solution onto flat silicon-coated Petri dishes and allowed to dry for $24 \mathrm{~h}$, at room temperature and at $35 \%$ relative humidity. Dried films were peeled off manually using spatula and stored in the desiccator prior to characterization. Starch was dissolved in de-ionized hot $\left(70^{\circ} \mathrm{C}\right)$ water with constant stirring. Then starch and chitosan solutions were mixed together at different proportions. Composite films were prepared by solution casting at the same parameters mentioned above. Thickness of films was maintained to $100 \mu \mathrm{m}$.

\section{Determination of the mechanical properties of the films \\ Mechanical properties (Tensile Strength and Elongation at Break) of the films were investigated by the Universal Testing Machine (Hounsfield series S testing machine, UK, H50 KS-0404) with a crosshead speed of $1 \mathrm{mms}^{-1}$ at a span distance of $25 \mathrm{~mm}$. The dimensions of the test specimen were: $60 \mathrm{~mm} \times 15 \mathrm{~mm} \times 0.01 \mathrm{~mm}$. The experiment was carried out according to the European standard (ISO/DIS 527-1:2010).}

Determination of the thermal properties of the films
The thermal test of the films was taken using computer controlled Differential Scanning Calorimeter (Model: DSC-60 Supplier: Shimadzu corp.). the temperature range was maintained at $30^{\circ} \mathrm{C}$ to $500^{\circ} \mathrm{C}$ and the temperature was increased at a rate of $10^{\circ} \mathrm{C} / \mathrm{min}$. the flow of nitrogen gas was $20 \mathrm{ml} / \mathrm{min}$. sample weight were $7.82 \mathrm{mg}$.

\section{Fourier Transform Infra Red (FTIR) spectroscopy}

FTIR spectra of the films were recorded using a spectrum one spectrophotometer (Perkin-Elmer) equipped with an attenuated total reflectance (ATR) device for solids analysis and a high linearity lithium tantalite (HLLT) detector. Spectra were analyzed using the spectrum 6.3 .5 software. Films were stored at room temperature for 72 minutes in a desiccator containing saturated $\mathrm{NaBr}$ solution to ensure stabilized atmosphere of $59.1 \% \mathrm{RH}$ at $20^{\circ} \mathrm{C}$. Films were then placed onto a zinc selenide crystal, and the analysis was performed within the spectral region of $650-4000 \mathrm{~cm}^{-1}$ with a 16 scans recorded at a $4 \mathrm{~cm}^{-1} 10$ resolution. After attenuation of total reflectance and baseline correction, spectra were normalized with a limit ordinate of 1.5 absorbance units. Resulting FTIR were compared in order to evaluate the effects of starch filling in the chitosan-based films, based on the intensity and shift of Vibrational bands. 


\section{Scanning Electron Microscopy analysis (SEM)}

Film samples $(5 \times 5)$ were deposited on an aluminum holder and sputtered with gold-platinum (coating thickness, 150-180 $\mathrm{A}^{\circ}$ ) in a Hummer IV sputter coater. SEM photographs were taken with a Hitachi S-4700 FEG-SEM scanning electron microscope (Hitachi Canada Ltd., Mississauga, ON, Canada) at a magnification of $40000 \times$, at room temperature. The working distance was maintained between 15.4 and $16.4 \mathrm{~mm}$, and the acceleration voltage used was $5 \mathrm{kV}$, with the electron beam directed to the surface at a $90^{\circ}$ angle and a secondary electron imaging (SEI) detector.

\section{Degradation test}

Degradation tests of the films were performed under humid soil at ambient condition. Up to three weeks of the tests were carried out. Films ware placed inside 10 $\mathrm{cm}$ depth of humid soil and at set time points: samples were taken out, cleaned and kept inside desiccators prior to weighing. The formula employed was:

Weight loss $\%=\{(\mathrm{Wb}-\mathrm{Wa}) / \mathrm{Wb} \times 100\}$, where, $\mathrm{Wb}=$ weight before placement in soil

$\mathrm{Wa}=$ weight after taken out and cleaned

\section{Statistical analysis}

For each measurement, five samples in each replicate were tested. Analysis of variance and Duncan's multiple-range tests were used to perform statistical analysis of all results, using PASW Statistics Base 18 software (SPSS Inc., Chicago, IL, USA). Differences between means were considered to be significant when $p \leq 0.05$.

\section{Results and Discussion Mechanical properties of chitosan reinforced starch- based composite films}

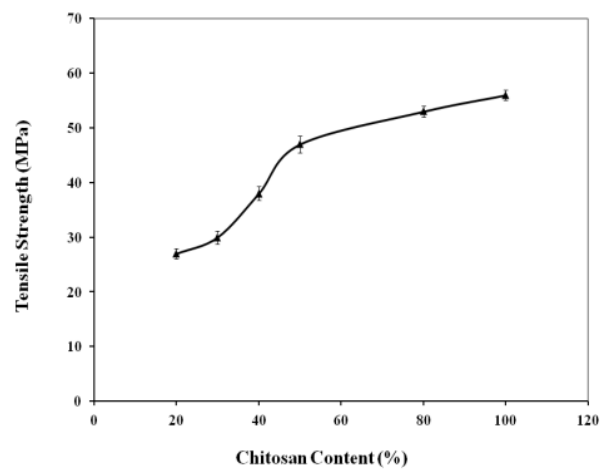

Fig. 2. Effect of chitosan on tensile strength of starch-based film

\section{Effect of acacia catechu on mechanical properties of starch/chitosan film}

Tensile strength (TS) values of chitosan/starch-based films were improved significantly with the addition of acacia catechu. Because acacia catechu is natural colored resin, like other natural resin it enhances mechanical properties of the film. Fig.4 shows the effect of acacia catechu on TS values of starch-based films. For $0.05,0.1,0.15,0.2 \%$ of addition of acacia
Chitosan (20-80\% w/w) was added in starch-based films to investigate the effectiveness of chitosan as reinforcing filler. Tensile Strength (TS) values of starch-based films was improved significantly $(p \leq 0.05)$ with the addition of chitosan. Fig. 2. shows the effect of chitosan on TS values of starch-based films. Far 20, 30, 40, 50 and $80 \%$ addition of chitosan, the TS values were observed to be $27,30,38,47$ and $53 \mathrm{MPa}$ respectively. The starch-based films became brittle below $20 \%$ chitosan content. So, in this investigation, the minimum amount of chitosan was maintained to 20 $\%$ ( by wt). it may be mention here that only starch could not form films by solution casting. The TS of chitosan films was found to be $56 \mathrm{MPa}$ (denoted $100 \%$ chitosan in figure). The $50 \%$ chitosan content starchbased films were almost transparent but below 50\% chitosan containing films was opaque in nature. With the rise of strength and modulus, the EB values of the starch-based films decreased monotonously due to chitosan addition (Fig. 3). The EB values of 20, 30, 40, 50 and $80 \%$ chitosan content films were $23,22,19,16$ and 12 percent respectively. Chitosan acted as a reinforcing agent in starch-based biodegradable films. Thus, higher content of chitosan can render the films stiffer. As result, decrease in EB values was observed. Similar result were reported by Pinotti et al., (2007) who indicated the reduction in methyl cellulose film flexibility with increasing chitosan concentration. Khan et al., (2012) reported that chitosan incorporation (5$36 \%$ by wt) in methylcellulose-based films significantly improved the strength of the films with the reduction of viscoelasticity. The $50 \%$ chitosan containing starchbased films was considered as the optimum because the film has good strength (47 MPa) and modulus (550 $\mathrm{MPa})$ and optimum EB (16\%) values. Moreover, the appearance of the films was quite transparent.

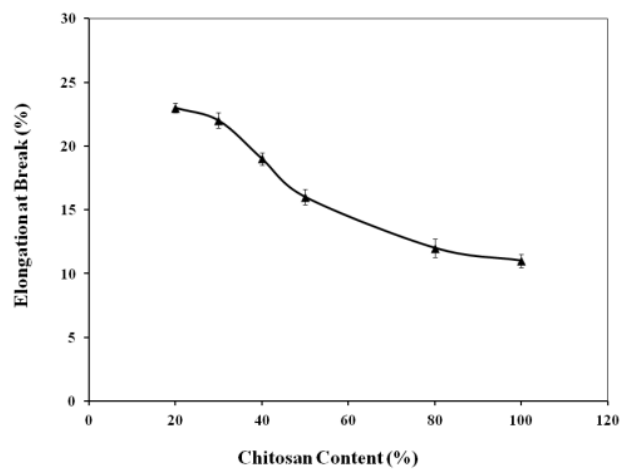

Fig. 3. Effect of chitosan on elongation at break of starch-based film

catechu, the TS values were observed to be $35,45,60$, $62 \mathrm{MPa}$ respectively. The acacia catechu+starch+chitosan based films became brittle over $0.2 \%$ acacia catechu content. So, in this investigation, the maximum amount of acacia catechu was maintained to $0.2 \%(\mathrm{w} / \mathrm{w})$. Fig. 5 shows with the rise of strength, the EB values of the acacia catechu+starch+chitosan based films decreased monotonously due to the acacia catechu addition. The 
EB values of $0.05,0.10,0.15,0.2$ (wt $\%$ ) of addition of acacia catechu the composite films were 22, 19, 13 and

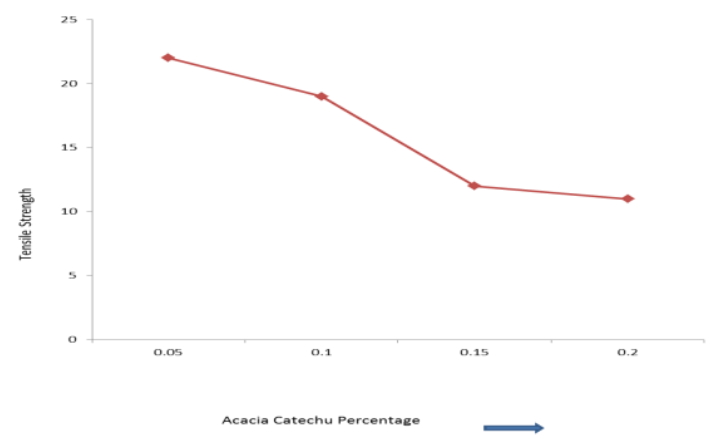

Fig. 4. Effect of Acacia Catechu on tensile strength of starch-chitosan based films

\section{Thermal properties of starch+chitosan+acacia catechu film}

The TGA thermograms for Starch+Chitosan+Acacia Catechu showed in Fig. 6 In this experiment, weight of the film (Starch+Chitosan+Acacia Catechu) was taken $7.82 \mathrm{mg}$. The TGA data for Starch+Chitosan+Acacia Catechu showed two steps in weight loss: one at $100^{\circ} \mathrm{C}$ and another at $390^{\circ} \mathrm{C}-400^{\circ} \mathrm{C}$. Total weight loss at $107.85,226.85,294.66,397.70,561.91{ }^{\circ} \mathrm{C}$ is 4.802 ,
12, respectively. Acacia catechu acted as a reinforcing agent in Chitosan/starch-based biodegradable films.

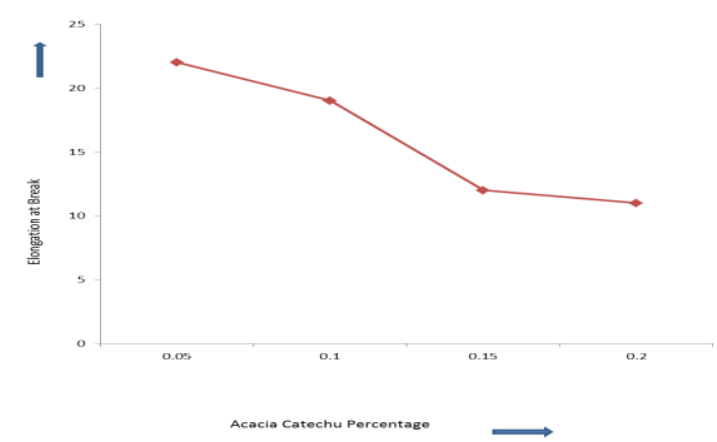

Fig. 5. Effect of Acacia Catechu on elongation at break of starch-chitosan blends films.

$13.755,16.169,11.686$ and $15.71 \%$, respectively. At temperature between $120^{\circ} \mathrm{C}-130^{\circ} \mathrm{C}$ high density poly ethylene degrades completely but this film (Starch+Chitosan+Acacia Catechu) at $359.70^{\circ} \mathrm{C}$ degrades only $16.169 \%$. So this biodegradable colored film in comparison with HDPE (High Density Poly Ethylene) showed better thermal stability.

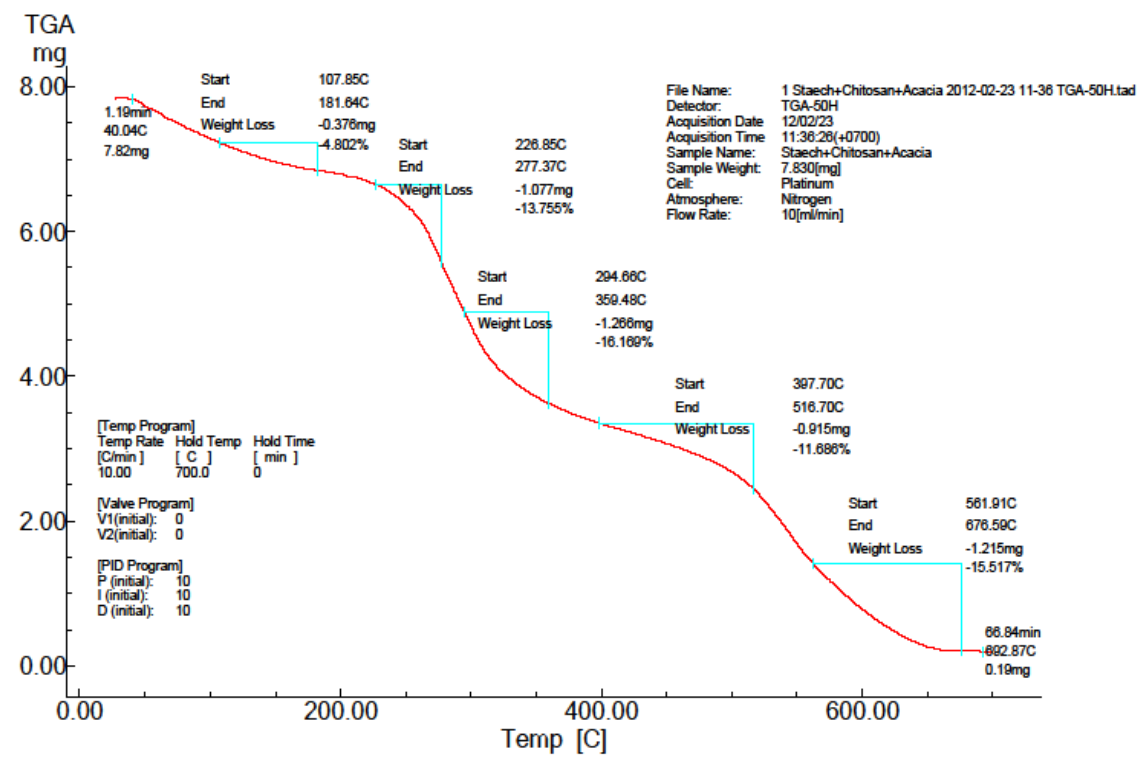

Fig. 6. Thermo-gravimetric analysis of starch + chitosan + acacia catechu film

\section{Fourier Transform Infrared Radiation Spectroscopic}

\section{Analysis}

The absorption peaks of the pure chitosan film (Fig. 7) were mainly assignable to the stretching of intra and intermolecular $\mathrm{O}-\mathrm{H}$ and $-\mathrm{CH}_{2} \mathrm{OH}$ vibrations at 3007 $\mathrm{cm}^{-1}$ overlapped with stretching $-\mathrm{NH}_{2}\left(2922 \mathrm{~cm}^{-1}\right)$ and $-\mathrm{NH}$ secondary amides vibrations $\left(2852 \mathrm{~cm}^{-1}\right)$. In addition, $2312 \mathrm{~cm}^{-1}$ corresponds to symmetric and The FT-IR spectrum of pure starch film is represented in Fig. 8. The peak at $1157 \mathrm{~cm}^{-1}$ was found due to the $\mathrm{C}-\mathrm{O}$ stretching of the $\mathrm{C}-\mathrm{OH}$ group in starch. The asymmetric $\mathrm{C}-\mathrm{H}$ vibrations. Amide I vibrational mode at $1745 \mathrm{~cm}^{-1}$ and Amide II at $1458 \mathrm{~cm}^{-1}$ were also clearly observed. The stretching $\mathrm{C}-\mathrm{N}$ vibration appeared at $1238 \mathrm{~cm}^{-1}$ and stretching $\mathrm{C}-\mathrm{O}$ band came at $1159 \mathrm{~cm}^{-}$ ${ }^{1}$. Other peaks (from 1097, 1028 and $721 \mathrm{~cm}^{-1}$ ) appeared from water molecules present in chitosan characteristic peak at $1099 \mathrm{~cm}^{-1}$ and $1020 \mathrm{~cm}^{-1}$ were attributed to $\mathrm{C}-\mathrm{O}$ stretching $\mathrm{f}$ the $\mathrm{C}-\mathrm{O}-\mathrm{C}$ group in the anhydroglucose ring. The peak frequencies at 3612, 
3730 and $3857 \mathrm{~cm}^{-1}$ were attributed to $\mathrm{O}-\mathrm{H}$ group

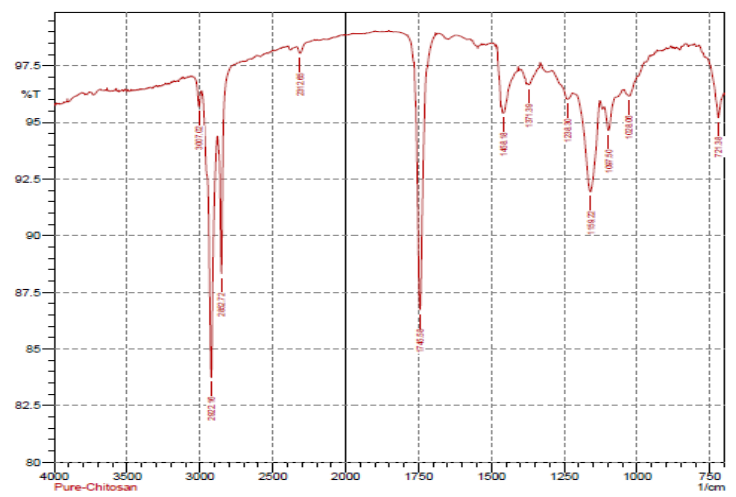

Fig. 7. FT-IR spectrum of pure chitosan film

The chitosan/starch-based film was investigated to find out the molecular interactions between chitosan and starch. The spectrum is represented in Fig. 9 of starchchitosan blend film. Both Amide I and Amide II peaks were not shifted. Both the peaks appeared at $1745 \mathrm{~cm}^{-1}$ and $1458 \mathrm{~cm}^{-1}$. The stretching $\mathrm{C}-\mathrm{N}$ vibration appeared at $1236 \mathrm{~cm}^{-1}$ that was slightly lower than pure chitosan $\left(1238 \mathrm{~cm}^{-1}\right)$. On the other hand, the stretching $\mathrm{C}-\mathrm{O}$ band came at $1161 \mathrm{~cm}^{-1}$ that was slightly higher than pure chitosan $\left(1159 \mathrm{~cm}^{-1}\right)$. The main characteristic peak $\left(1099 \mathrm{~cm}^{-1}\right)$ of starch $(\mathrm{C}-\mathrm{O}$ stretching from C-O-C group) was not shifted. From this spectrum, this is clearly revealed that chitosan was not chemically reacted with starch, as expected. Here, a bio-blend was formed between chitosan and starch.

The Chitosan+Starch+Acacia Catechu-based film were investigated to find out the molecular interactions

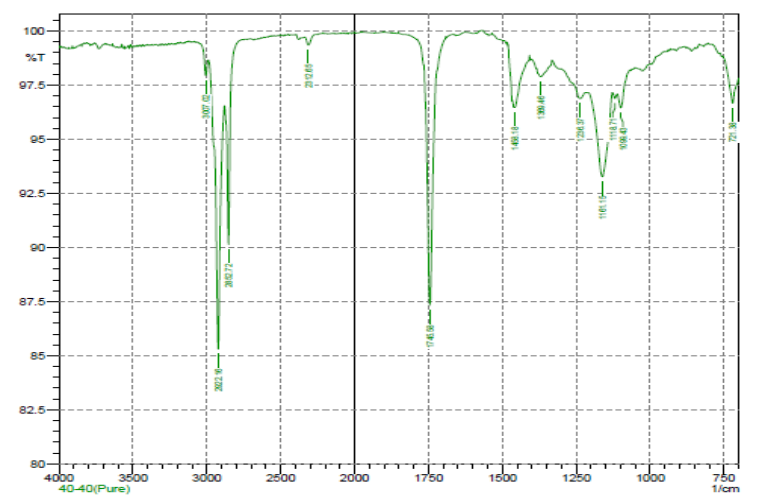

Fig. 9. FT-IR spectrum of starch/chitosan film

\section{Morphological study by using SEM}

Fig. 11 represents the surface morphology of chitosan (a) and chitosan reinforced starch-based (b) films. The surface of chitosan films appeared a homogenous, smoother and denser film surface with no gross defects. The smooth and homogenous surface of the films is an stretching.

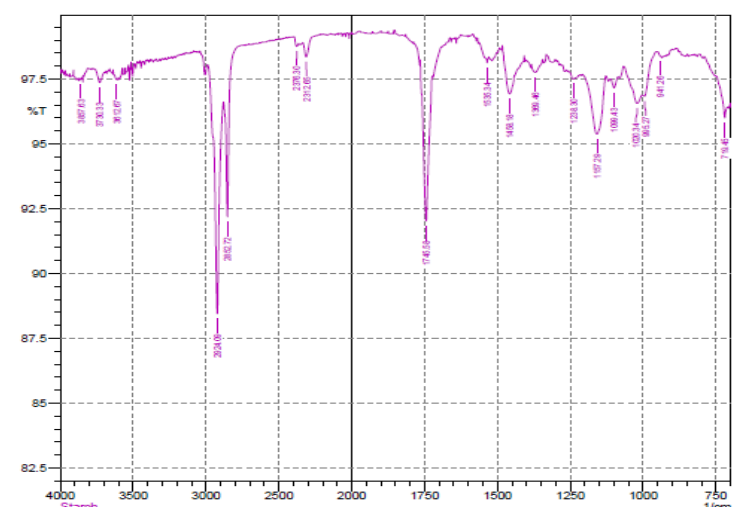

Fig. 8. FT-IR spectrum of pure starch

between chitosan, starch and acacia catechu. The spectrum is represented in Fig. 10 of Chitosan+Starch+Acacia Catechu blend film. Both Amide peaks $\left(1745 \mathrm{~cm}^{-1}\right.$ and $\left.1458 \mathrm{~cm}^{-1}\right)$ are slightly shifted to $1737 \mathrm{~cm}^{-1}$ and $1548 \mathrm{~cm}^{-1}$. Acacia Catechu might be reacted with amide group of chitosan or may be hydrogen bond formed. The absorption peaks (3302 $\mathrm{cm}^{-1}$ and $2872 \mathrm{~cm}^{-1}$ ) of the Chitosan+Starch+Acacia Catechu film found broader than the absorption peaks of the pure chitosan film assignable to the stretching of intra and intermolecular $\mathrm{O}-\mathrm{H}$ and $-\mathrm{CH}_{2} \mathrm{OH}$ vibrations at $3007 \mathrm{~cm}^{-1}$ overlapped with stretching $-\mathrm{NH}_{2}\left(2922 \mathrm{~cm}^{-1}\right)$ -NH secondary amides vibrations $\left(2852 \mathrm{~cm}^{-1}\right)$ because of O-H bond in acacia catechu. A major peak appeared in $1016 \mathrm{~cm}^{-1}$ which indicates $\mathrm{C}-\mathrm{O}$ bond in acacia.

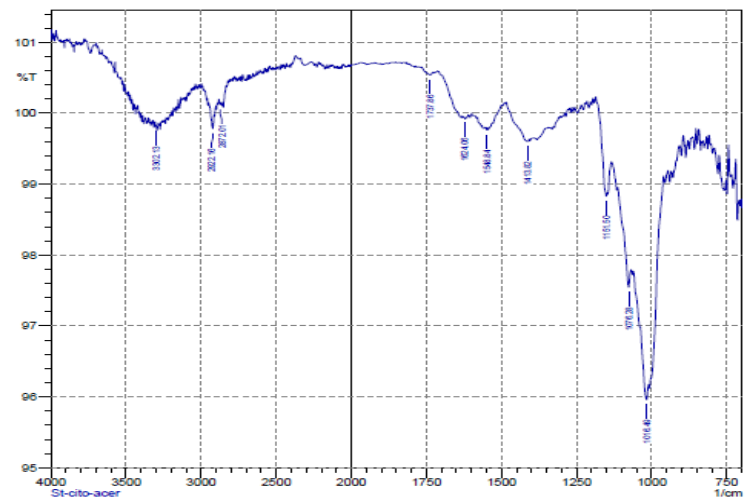

Fig. 10. FT-IR spectrum of acacia catechu/starch/chitosan film

indicator of the structural integrity of the observed films and thus good mechanical properties were obtained. It also indicated better solubilization and homogenization of chitosan in aqueous medium. But chitosan reinforced starch-based films showed rough and irregular surface with bubbles as compared to pure chitosan films. 


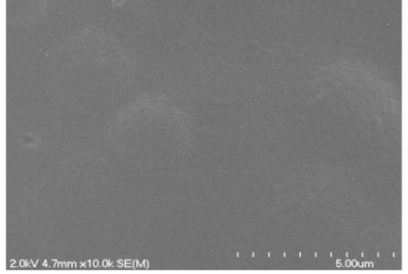

(a)

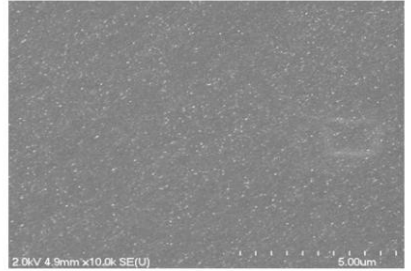

(b)

Fig. 11. Surface morphology of (a) chitosan film, and (b) chitosan reinforced (50\% by wt) starch-based film.

\section{Surface morphology of the final starch+chitosan+acacia catechu films}

The surfaces of the Acacia Catechu $(0.15 \%$ by wt) containing chitosan/starch (50:50)-based films were investigated by Scanning Electron Microscopy (SEM) from low to high magnification. The images are presented in Fig. 11(a-i). In open eye, the surface of the films was very clear, homogenous and shiny. But at $\times 30$ magnifications (a), phase separation is clearly shown which indicated that chitosan/starch (biopolymers) and acacia catechu (natural resin) did not react with each other, as expected. Natural resin was added to improve the mechanical strength and to make the film bioactive to protect the packaged food against bacteria. At medium magnification $(\times 50$ and $\times 100)$, represented by (b) and (c), phase separation is more clearly visible.

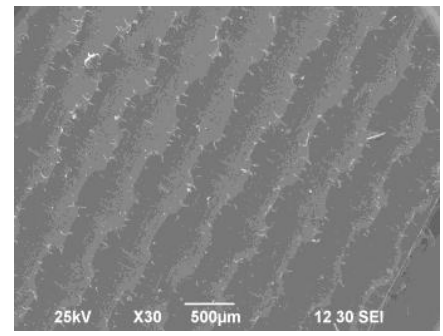

(a)

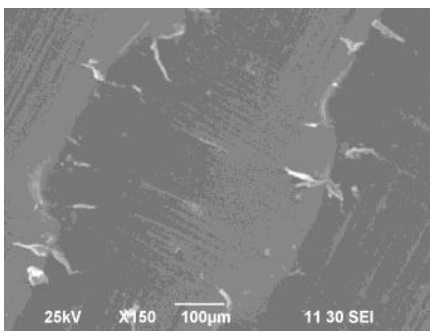

(b)

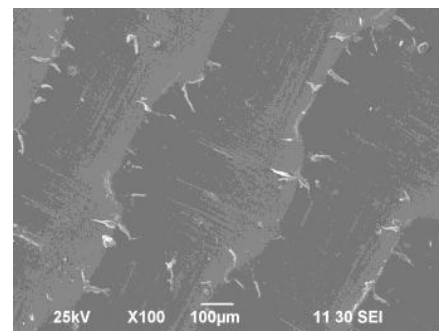

(c)

Fig. 11(a-c). Surface morphology of starch + chitosan + acacia catechu film

With the rise of magnification from $\times 250$ to $\times 1000$; Fig. 11 (d-e), few defects are found and surfaces look heterogeneous. Dramatic image is observed at $\times 3500$ magnification (f). Here surface is cleaner and appearance is much better than other low magnification images.
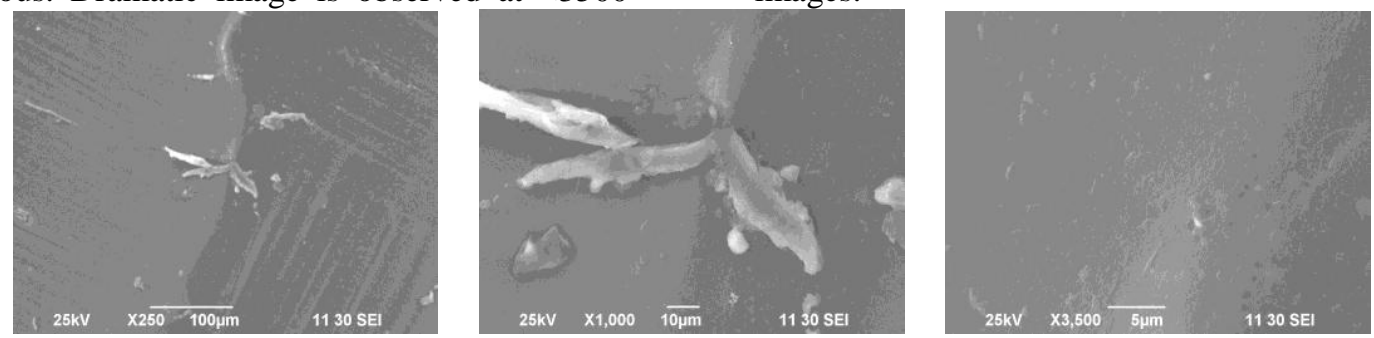

Fig. 11(d-f). Surface morphology of starch + chitosan + acacia catechu film

At very high magnifications from $\times 7500$ to $\times 40000$; Fig. 11 (g-i), surfaces of the films look much better. At $\times 40000$ magnifications (i) the SEM image of the film is fantastic and indicated more homogeneity. Films are clear from bubbles and irregularities. From the image, it is concluded that a homogeneous film surface appeared using three natural materials. Two biopolymers (chitosan and starch) and one natural resin (acacia catechu) mixed homogeneously and made a fantastic bio-blend for the preparation of biodegradable film for food packaging application.
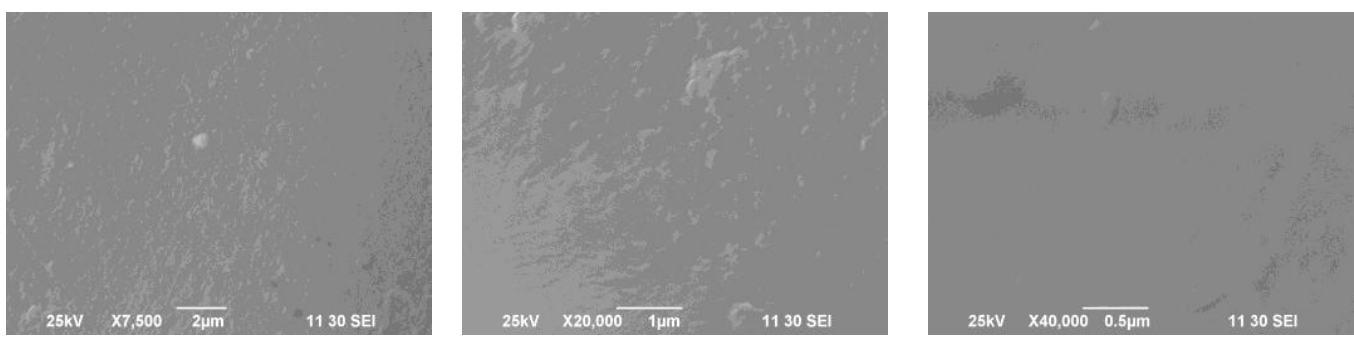

Fig. 11 (g-i). Surface morphology of starch + chitosan + acacia catechu film 


\section{Water uptake}

The water uptake behavior of chitosan film and chitosan (50\% by wt) reinforced starch-based composite films are shown in Fig. 12. It was found that water uptake of starch/chitosan composite films were much lower compared to native chitosan films. Both type of films absorbed water very rapidly. After 2 min, chitosan film absorbed $160 \%$ water, whereas the starch/chitosan film absorbed $96 \%$ water. At $10 \mathrm{~min}$, chitosan reached to $176 \%$ and starch/chitosan arrived at $125 \%$ of water uptake then both the films showed a gradual decrease of water uptake and indicated the loss of its mass. After 30 min, the water uptake of chitosan and starch/chitosan films showed 155 and $101 \%$ of water uptake respectively. Chitosan is water soluble as the salts of various acids present in D-glucoseamino unit. Partially acetylated chitosan has about 50\% D-glucoseamine unit that dissolves in water. The starch/chitosan film had better stability in water compared to native chitosan films. The reason could be due to the network formation between starches with chitosan, which prevented water molecules into the films. But both films showed strong affinity of water uptake that indicated strong hydrophilic nature. Both starch and chitosan had plenty of free hydroxyl groups and as a result within few minutes, a significant amount of water penetrated into the films. But the advantage is the reduction of water uptake due to the reinforcement of chitosan in starchbased films. For example, after 10 min of immersion in water the starch/chitosan film reduced to $34.83 \%$ of

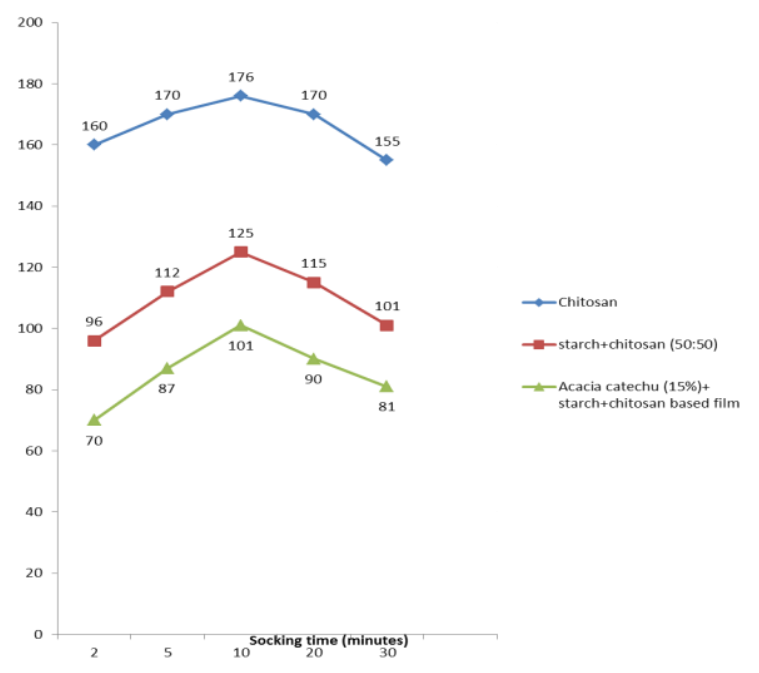

Fig. 12. Water uptake of pure chitosan film, chitoan/starch film and acacia catechu $(0.15 \%)+$ starch + chitosan film

\section{Conclusions}

Biodegradable film made of Starch, Chitosan and Acacia Catechu was successfully developed by solution casting. Acacia Catechu contributed to the improvement of tensile strength in starch/chitosan films. This film showed good thermal stability also. Structural characterization was done by FT-IR. The surface water uptake compared to native chitosan. So, chitosan improved the stability of the starch-based composite films in aqueous medium.

But films with acacia catechu were almost static. After $30 \mathrm{~min}$, the water uptake of acacia catechu (0.15 wt \%) +starch+chitosan based film, native chitosan and starch/chitosan films reached to $81 \%, 155 \%$ and $101 \%$ respectively.

Acacia catechu (0.15 wt \%) +starch+chitosan based film had better stability in water compared to chitosan or starch/chitosan based films. Acacia catechu might be create a network with the biopolymers (chitosan and starch) and formed network, which prevented water molecules penetration into the films.

\section{Soil degradation test}

In Fig. 13 weight loss (\%) was plotted against the degradation time in soil (week). It was observed that the weight loss $(\%)$ is increased with the increasing time. After one week, weight loss is $0.2 \%$, after two weeks, weight loss is $0.5 \%$, after three weeks, weight loss is $3 \%$, after four weeks, weight loss is $5 \%$. From this investigation, it was expected that this film will be biodegradable in soil in less than 6 months. Moreover, in the prepared films, Acacia catechu, starch and chitosan, all are natural fiber and totally biodegradable. So, the film did not lose its total inherent biodegradable character after mixing but withstand its stability for longer period.

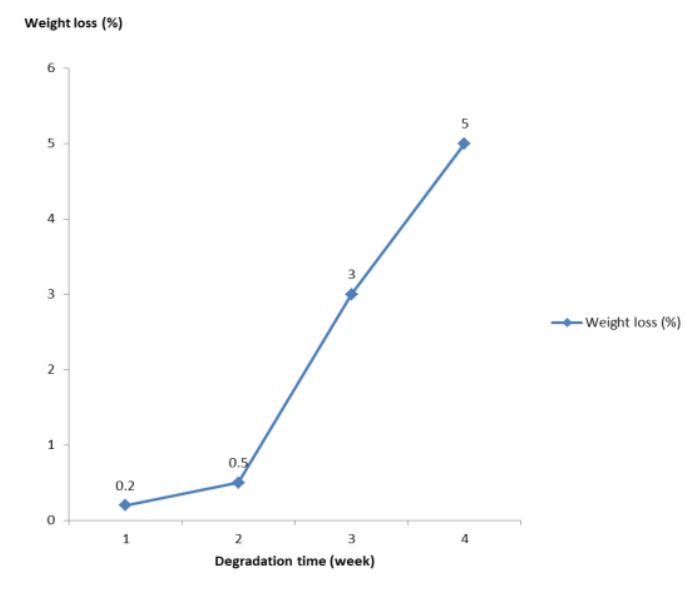

Fig. 13. Soil degradation of chitosan/starch based film with acacia catechu $(0.15 \%)$

morphologies indicated better homogenization of the three biopolymers (Starch, Chitosan and Acacia Catechu). Water uptake was lower for Acacia Catechu incorporated film than Starch/Chitosan film. Finally, degradation rate in soil is satisfactory also. The prepared films can be used as the colored biodegradable packaging films. 


\section{References}

Arnades, J. M.; Bilbao, J. and Lopez-Valerio, D. 2004. Reciclado de residues plasticos. Revista Iberoamericana de Polímeros, 5: 28-45.

Arunachalam, M; Raj M. M; Mohan N and Mahadevan A; 2003. Biodegradation of Catechin. Proceedings of the Indian National Science Academy. B69 No. 4:353-370.

Ban, W. P.; Song, J. G.; Argyropoulos, D. S. and Lucia, L. A. 2006. Influence of natural biomaterials on the elastic properties of starch-derived films: An optimization study. Industrial \& Engineering Chemistry Research, 45:627-633.

Chen, M. C.; Yeh, G. H. C. and Chiang, B. H. 1996. Antimicrobial and physicochemical properties of methylcellulose and chitosan films containing a preservative. Journal of Food Processing and Preservation, 20:379-390.

Garcia, N. L.; Ribba, L.; Dufresne, A.; Aranguren, M. I. and Goyanes, S. 2009. Physico-mechanical properties of biodegradable starch nanocomposites. Macromolecular Materials and Engineering, 294(3):169-177.

Helander, I. M.; Nurmiaho-Lasilla, E. L.; Ahvenainen, R.; Rhoades, J. and Roller, S. 2001. Chitosan disrupts the barrier properties of the outer membrane of Gram-negative bacteria. International Journal of Food Microbiology, 71:235-244.

HongguanDaia; Peter R. Changb; JiugaoYua; XiaofeiMaa. 2008. N,N-Bis (2 hydroxyethyl) formamide as a New Plasticizer for Thermoplastic Starch. Starch, 60:676-684.

Indian Council of Forestry Research and Education, Dehradhun. Khair(Acacia Catechu). Dehradhun, Forest Research Institute. http://www.frienvis.nic.in/khair.ht
Mathew, A. P. and Durfresne, A. 2002. Plasticized waxy maize starch: effect of polyols and relative humidity on material properties. Biomacromolecules, 3:1101-1108.

Möller, H.; Grelier, S.; Pardon, P. and Coma, V. 2004. Antimicrobial and physicochemical properties of chitosan-HPMC-based films. Journal of Agriculture and Food Chemistry, 52:6585-6591.

Pagella, C.; Spingo, G. and Faveri, D. M. 2002. Characterization of starch based edible Coatings. Food Bioproduct and Processing, 80:193-198.

Parra, D. F.; Tadini, C. C.; Ponce, P. and Lugao, A. B. 2004. Mechanical properties and water vapor transmission in some blends of cassava starch edible films. Carbohydrate Polymers, 58:475-481.

Roller, S. and Covill, N. 1999. The antifungal properties of chitosan in laboratory media and apple juice. International Journal of Food Microbiology, 47:67-77.

Shorgen, R. L. 1998. Biopolymers from renewable resources. In: Kaplan, D. L. (Editor). SpringerVerlag, Berlin.

Thuwall, M.; Boldizar, A. and Rigdahl, M. 2006. Extrusion processing of high amylase potato starch materials. Carbohydrate Polymers, 65:441-446.

Wang, X. L.; Yang, K. K. and Wang, Y. Z. 2003. Properties of starch blends with biodegradable polymers. Journal of Macromolecular Science, Part C, 43:385-409.

Xu, Y. X., Kim, K. M., Hanna, M. A. and Nag, D. 2005. Chitosan-starch composite film: Preparation and characterization. Industrial Crops and Products, 21:185-192.

Xu, Y. X.; Miladinov, V. and Hanna, M. A. 2004. Synthesis and characterization of starch acetates with high substitution. Cereal Chemistry, 81:735740. 